Golo Föllmer, Alexander Badenoch (eds.)

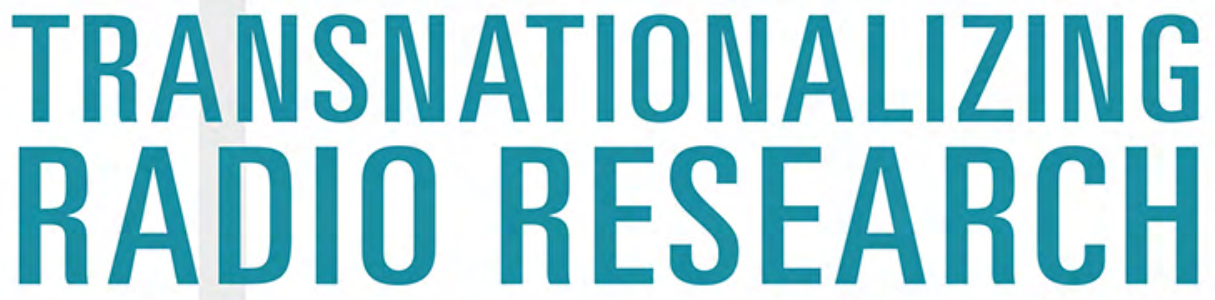
NEW APPROACHES TO AN OLD MEDIUM

[transcript] Media Studies 
Golo Föllmer, Alexander Badenoch (eds.)

Transnationalizing Radio Research

Media Studies | Volume 42 

Golo Föllmer, Alexander Badenoch (eds.)

\section{Transnationalizing Radio Research}

New Approaches to an Old Medium

[transcript] 
Bibliographic information published by the Deutsche Nationalbibliothek

The Deutsche Nationalbibliothek lists this publication in the Deutsche Nationalbibliografie; detailed bibliographic data are available in the Internet at http://dnb.d-nb.de

\section{(c) $(1)(\Theta)$}

This work is licensed under the Creative Commons Attribution-NonCommercial-NoDerivatives 4.0 (BY-NC-ND) which means that the text may be used for non-commercial purposes, provided credit is given to the author. For details go to http://creativecommons.org/licenses/by-nc-nd/4.0/

To create an adaptation, translation, or derivative of the original work and for commercial use, further permission is required and can be obtained by contacting rights@ transcript-verlag.de

Creative Commons license terms for re-use do not apply to any content (such as graphs, figures, photos, excerpts, etc.) not original to the Open Access publication and further permission may be required from the rights holder. The obligation to research and clear permission lies solely with the party re-using the material.

\section{(C) 2018 transcript Verlag, Bielefeld}

Cover layout: Maria Arndt, Bielefeld

Typeset: Anja Richter

Printed by Majuskel Medienproduktion $\mathrm{GmbH}$, Wetzlar

Print-ISBN 978-3-8376-3913-1

PDF-ISBN 978-3-8394-3913-5 


\title{
Accented Radio in Miami and New Orleans
}

\author{
Katie Moylan
}

"Accented radio" is an idea I developed drawing from Hamid Naficy's (2001) concept of accented cultural production to explore a specifically transcultural mode of radio production. Through analyses of accented radio production, I argue here that transcultural radio programs can function as an alternative to often reductive top-down radio representations of marginalized and minority communities. My use of this concept builds on Naficy's theory of accented film production as a transcultural mode of production which signifies not only the "accent" of those represented but also the producers' experiences of displacement, movement and settlement which are then embedded in the text produced. An accented mode of production incorporates the sense of duality characteristic of transnational experience, as the migrant or minority subject speaks from a migrant/minority perspective to a migrant/minority community, yet from within the normative communication structures of the host country (Naficy 2001) and/or from within a public sphere characterized by reductive representations of the given community and often by limited spaces for community selfexpression. "Accented radio" provides a critical lens incorporating exploration of elements of production practice (guest and topic choices; information provision; air time for callers in to the show) which reinforce community-building for marginalized and minority communities on air. ${ }^{1}$ Deploying accented radio as an embodiment of transcultural community production enables exploration of what John Hartley (2000) has identified as radio's community-building tendencies, allowing for a combined analysis of aesthetic, political and production components which comprise community forms of programming.

This chapter draws on research carried out in the USA in 2015-16 to examine selected community-focused programming from New Orleans and Miami as examples of accented radio. Accented radio programs are arguably more possible in community radio. Here, the material structures enable those elements of community radio which facilitate greater community representation and

$\mathbf{1} \mid$ See also S. Vertovec, who developed the idea of accented radio separately in an analysis of Berlin's Radio MultiKulti (Vertovec 2008). 
self-representation such as broadcasting live, extended phone-in opportunities and expanded time allocated for discussion and debate of community issues. The project of community radio has historically been conceived of as a grassroots initiative to empower marginalized communities by providing broadcast opportunities for community self-representation (Lewis/Booth 1989; Barnard 2000). I argue that in addition to this crucial capacity for community expression, community radio (ideologically and materially) facilitates communicative avenues for alternative articulations of marginalized and minority experiences which negotiate, counter and challenge normative discursive framings of race which often otherwise dominate mainstream media.

Within the spectrum of broadcast media, community radio has been recognized as 'third sector' media (Lewis 2008) with the recognized capacity to provide alternative fora to those available on public service and commercial radio. In theory and often in practice, community radio thus embodies and promotes a bottom-up, grassroots approach, conceived of as inherently inclusive and allowing for diverse approaches to production practice, in both policy and individual station remits. Broadcasting from within geographically, politically and socially specific contexts, community radio 'covers different approaches, attitudes and precepts that are sometimes defined in terms of modern versus traditional, progressive versus conservative, or even revolutionary versus reactionary' (Barnard 2000: 68). Community radio is additionally typified by a multiplicity of production approaches, which in turn produce greater scope for community expression (Lewis and Booth 1989; Day 2007; Scifo 2008; Gordon et al 2009; Moylan 2013). Accented radio enables grassroots articulations of community issues and expression of community experiences in distinct ways depending on local and regional contextual factors. The format of community radio is consequently structurally well situated to produce such programming, by remit.

Naficy (2001) suggests that 'accented' cultural texts communicate by “expressing, allegorizing, commenting upon, and critiquing the home and host societies and cultures and the deterritorialized conditions of the [producers]." (2001: 4) "Accent" can be initially defined as a heard vocal sounding, communicating regional and social identity but also affiliations: community, educational, faith-based, linguistic (Naficy 2001). While each of us speaks with an accent, value is conferred upon individual accents within a hierarchy in which accents are invested with different degrees of currency, readability and social capital. Given all these factors, "accent is one of the most intimate and powerful markers of group identity and solidarity, as well as of individual difference.” (Naficy 2001: 23) Accent in radio functions simultaneously at an aesthetic level: the heard voice and modes of delivery, and at a social level: accent as articulation of identity but also of situatedness. Accented radio programs additionally and crucially "speak" to and engage with their target communities simply 
through articulating experiences and issues in the accent - and first language of that community. An accented radio program therefore functions at the local level - speaking not only to the community whose members produce it but also to other local (and marginalized) communities - and at the same time articulates a wider, shared and transnational perspective. Yet accented radio retains a specificity through which the material conditions of program production can be heard alongside articulations of individual and community identity. Thus accented radio enables us to listen for identity articulation through uses of voice and delivery within both a localized format and simultaneously within the larger hegemonic paradigm of a normative and co-opted multiculturalism which primarily serves to reinforce established hierarchies.

\section{FIRST LANGUAGE COMMUNITY PROGRAMS IN New OrLeans}

Established as a city in 1718, New Orleans has been incorporated in its current municipal form longer than almost any other North American city. Possessing a unique claim to a distinct cultural richness and identity, it is regularly described (by locals and outsiders alike) as the northernmost Caribbean city, imbued with characteristics of a Caribbean identity in its diversity and emphasis on musical cultures, local festivals and vivid cuisine. Yet in other ways it is quintessentially American; the established infrastructural problems negotiated by New Orleans are characteristic of those faced by other struggling US cities: declining and insufficient schools, inadequate health care, neglected municipal spaces, unreliable public transport. These fundamental municipal problems have only become more pronounced following the devastation of Hurricane Katrina in 2005 .

Community station WRBH's "first language" programming (Langer 2005; Moylan 2013) for Haitian, Spanish and Vietnamese communities reflects the city's linguistic and cultural diversity. WRBH FM was established with a remit to provide an on-air reading service for blind listeners; the station's call sign references the full name of "Reading Radio for the Blind and Print Handicapped." The station began broadcasting 24 hours a day in 1982 and, as of 2016 , WRBH has been the only radio station in the US providing a 24 -hour reading service on the FM frequency. In 2015 the station had four fulltime staff and broadcast from studios in a spacious house on Magazine Street in leafy uptown New Orleans. Station listenership in New Orleans extends well beyond the blind com-

2 Station Manager Natalia Gonzalez recognises that the word 'handicapped' in the station name is today considered offensive; as it is referenced by the call sign letter $\mathrm{H}$ it remains difficult to change this. (From interview with Gonzalez, 13 May 2015.) 
munity; while station resources do not stretch to research into listener numbers, recurring anecdotal evidence from conversations I had while in the city revealed that the daily morning reading aloud of the Times-Picayune newspaper on WRBH was a favorite feature for local professionals, who listened in their cars en route to work. Alongside the provision of its primary service of "reading radio" for blind listeners, WRBH also provides schedule space for linguistic community representation. The weekly schedule includes Haitian, Spanish and Vietnamese programs, all in the first languages of their target communities. La Voix d'Haiti and The Vietnamese Show began broadcasting on WRBH as responses to crises: amongst the Vietnamese community following Hurricane Katrina in 2005 and after the 2010 earthquake in Haiti. At time of writing, The Vietnamese Show on WRBH is the only radio show serving this established and sizeable community in New Orleans. The show has been produced and presented since 2008 by John-Hoa Nguyen, who works by day as an estate agent, and is broadcast between 7 and 8pm on Sundays. Nguyen acknowledges that he is well known in the Vietnamese community and that this is a source of community trust which helps him in presenting and producing the program:

I am lucky enough to be out there in the community quite often. I would say on the West Bank, $75 \%$ of the Vietnamese know me. And throughout the New Orleans metropolitan area I would say $50 \%$ or $60 \%$ of them know me. Every time there is a major function in the community they will ask me to get involved, because my voice is easy to be recognised.

I work with them as a link, because I can link them to different locations, to different people, and we can get together. (Interview with Nguyen, 20 May 2015)

Broadcast on Sundays between 5 and 6pm, La Voix d'Haiti usually incorporates a half hour of talk and discussion in French Creole, followed by a half hour of Haitian music. Producer and presenter Joseph H. Louis Jeune, known and broadcasting as Hector, describes the show's remit:

The purpose of me coming here is to engage the community, to tell them what's going on, to inform the community [...] What is important to me is to see whether I can have my community engaged. (Interview with Jeune, 13 May 2015)

Jeune stresses the importance of the Haitian show being broadcast in the 'first language' of the target audience, and describes how this informs how the community is situated in the city:

In my mind I'm talking to the whole community [...] I have in mind everybody when I'm talking [...] I see Haitian first. Unconsciously the show to me is just Haitian, before New Orleanian. (Ibid.) 
'First language' programming is immediately more accessible to ethnic and cultural communities in which the 'first language' of a majority of members is not English but that of their home or sending country. Hearing their first language spoken on air can confer a sense of belonging in community members in advance of the content of the program that follows. Nguyen too insists on the importance of broadcasting in his community's first language, saying that for the first generation of migrants from Vietnam,

their first language is still Vietnamese. But for most of the second generation who were born in the US, their primary language is English [...] My show is in Vietnamese because most of my listeners are of the first or one and a half generation [...] Maybe now and then we have speakers in English but then we translate simultaneously. (Interview with Nguyen, 20 May 2015)

Both Nguyen and Jeune acknowledge and appreciate the institutional support provided by WRBH for their programs.

The institutional and material support provided by WRBH crucially facilitates the ongoing production of all three 'first language' shows. Alongside their accessibility in relation to first language content and coverage of community issues is the more abstract but nonetheless crucial function of community building in a wider sense. Nguyen discusses the importance of The Vietnamese Show in reinforcing a shared sense of community for New Orleans Vietnamese community members:

The only thing that the Vietnamese have, that other people do not have, or at least we have it stronger, is we have a sense of belonging. See, once you have a sense of belonging, you belong to something, then that is part of you. So the Vietnamese, even though New Orleans is not their primary home of their choice, because their main home was in Vietnam but they were forced to exile, so they made New Orleans their permanent home. And they feel that New Orleans is their home so they have a stronger sense of belonging...

for us to be a community every one of us has to have that sense of belonging. And we have to instill that sense of belonging into people. Otherwise a community is nowhere to be found. (Interview with Nguyen, 20 May 2015)

This encapsulates the ways in which the Vietnamese community consider New Orleans home even as they recognize how this layers on top of their migration experiences (for the first generation) and their held sense of Vietnam as the 'original' home country. This complex identity position and sensibility is articulated and reinforced through The Vietnamese Show and La Voix d'Haiti, in broadcasted content, news and information about community events in the city. 


\section{Bridging layers of Haitian communities In Miami}

Miami's established and emergent diversity incorporates substantial Cuban and Haitian communities alongside smaller Caribbean and South American migrant groups and transient snowbirds. The city's cultural, experiential and linguistic diversity is expressed in myriad ways in a range of community-focused programs broadcast (mainly) on different AM radio stations in Miami. Spanish-language commercial stations WRHC AM and WAQI AM (broadcasting as Radio Mambí) serve Miami's Spanish-speaking Cuban and South American communities, while the Colombian community is primarily served by WSUA AM. In North Miami Beach, WSRF AM, the "first Haitian station in the Nation," broadcasts programs for and by Miami's sizeable Haitian community in a mixture of English and Creole-language programming. In some contrast, Miami's public radio station, the NPR-affiliate WLRN FM, broadcasts a mixture of local and national NPR programs entirely in English, with one exception. Radyo Lekol is an educational news program directed at the Haitian community, and was Miami's first radio program to be broadcast entirely in Haitian Creole. The show goes out on WLRN Monday through Friday at 9.05pm for 25 minutes. Within Radyo Lekol's educational format, Friday's show is hosted by Jan Mapou, who also runs a folklore museum in Little Haiti. The Friday show foregrounds "Haitian culture, traditions, music, folklores and the Creole language," as described on the show's webpage. ${ }^{3}$ Those producers and presenters I interviewed from both WSRF and WLRN's Radyo Lekol agreed that radio was the best medium to reaching members of the Haitian community, particularly newer migrants from Haiti.

Radyo Lekol was developed with an educational remit in response to the needs of Miami's Haitian community and is produced and presented entirely by members of that community. Program producer Carline Faustin describes the context informing the show's inception, and the decision to broadcast in Haitian Creole:

Not too many Haitian people actually are literate. [...] Especially the influx of the boat people, what they called them at the time, were people who were working on the farm, people who were just looking for a better life. The people who were already abroad or people who came from well-off families, they were taught in French. So therefore (reole was a speaking language, not so much a written language. (Interview with Carline Faustin, 8 April 2016)

Faustin's work in Haitian Affairs for the Miami area included developing educational material for newly arrived Haitian families and necessarily involved outreach in the dissemination of information to the community. This work

3 | From http://wlrn.org/programs/radyo-lekol, accessed 10 February 2017. 
led to her recognition that a radio show would be a good format for this, as she explains:

We felt like: wouldn't it be better to continue providing that service in Creole, to the Haitian community, so that [...] you're preparing them, you're informing them what is going on. And that is the purpose of Radyo Lekol. Radyo Lekol keeps the parent informed of what's going on in the community, and what's going on in the school system, what's coming, how the school is doing, how the children are doing, and everything else. (ibid.)

The program's name comes from its educational remit, and reflects the show's foregrounding of Creole as the program language: "It's not the same as French at all, because French is "école". But in Creole it's different. Sounds the same, but different." (Interview with Faustin) Radyo Lekol is produced and presented by a team of four people: Faustin, Simone Degraff, Cherol Marcelin and Jan Mapou. Situating the show's use of language consciously and reflexively is important to the producers, as Marcelin, who works as a linguist, explains:

I realize that the culture is very important, for the Haitian community, for any community, any diaspora, and although we have a cultural show [as part of Radyo Lekol] every Friday, I know that language is the forefront of the cultural list. So my show is focused on the language, and the people need to be reminded all the time of things they used to know in Haiti, and how it is important to know your language.

We came to this country with some kind of frustration about the use of the language, if you speak Creole in Haiti - that's how it used to be - you are not taken very seriously if you don't speak French or English. And they came into this country with this frustration, and this bad image of the language, so I realized that I make a choice, so I talk about the language and how it works...

When you are passionate about it, you can transmit that passion to others, and you can recognize that the language is a very important part of the culture, I've been doing that. But my main job is to give information! (Interview with Cherol Marcelin, 8 April 2016)

On WSRF's daily morning program The Morning Drive, banter, commentary and interviews are broadcast in a vibrant combination of Haitian Creole and English; or as one guest contributor called it, 'Cringlish'. This easy flow between English and Creole words and expressions is inherent to the show and practiced by hosts and guests alike and enables the show to speak from and to the experiences of the first and second generation Haitian-Americans who form the show's regular listenership. However, the show's insistence on using and combining both languages has been controversial to some members of the Haitian community. Rhonel Cinous, Fabiola Charles and Rebecca Laratte have been collectively producing and presenting on program The Morning Drive for over two years, although they each began work on the show at different times. 
In our group interview in spring 2016, the three young Haitian-American program hosts explained that this movement between English and Creole is quite deliberate, enabling them to speak to older and younger generations of the Miami Haitian community all at the same time through a mode of expression everyone can understand and relate to. Rhonel Cinous explains how the movement between Creole and English is inherent to the program's flow.

We know how to speak English, we grew up in the system, we learned Creole from our parents, we learned French, but our experience, and to be accurate, is the flow of it. That's how we speak daily.

And to give that reality, and of course our listeners are very diverse, so it does help, and our genuine experience is speaking like that (Interview with Rhonel Cinous, The Morning Drive, 19 April 2016)

This 'flow' is a quality which the medium of radio particularly lends itself to, of course; however the aesthetics of such a flow, in addition to appealing to listeners, also serves to situate the specific identity positions of the show's producerpresenters - and the show's project. Fabiola Charles describes the show's aim to consistently bridge the generations in the larger Haitian community:

Growing up, you can only hear older people on the radio. And you can never hear [...] the younger generation is never given a voice, to actually say anything.

For us, I feel like, the younger generation needs a voice in the community, and we need to be talking about something that's relevant to them. Because my dad listens to old news, what's going on in Haiti, but the new generation are not really interested in that, they can get that on social media. But they need something that's relevant, about what's going on in the community... that's what they want. So that's why we have this show, to build a bridge between the older generation and the new generation. (Interview with Fabiola Charles, The Morning Drive, 19 April 2016)

Critiques of the show's combination of Creole and English have primarily come from the older generations of their Haitian community listenership, who feel it is inconsistent and have approaches all three producers/presenters with their concerns. Yet all three feel the fluidity of flow between the two languages actually facilitates language learning, and in ways specific to each listener group within the larger Miami Haitian-American community, as Fabiola explains: "With your parents you speak Creole. With your friends you speak English. And then sometimes you need a balance. Like sometimes you take the English word, you put it into Creole, and it comes so naturally now." (Interview with Charles) Cinous agrees, saying, 
Creole was more of a third language for me. Because I grew up in the States, we had to learn English first, it was my first language with siblings, At home you speak as much Creole as you can, but then when you're in school or you're with friends, you're telling a story and when you're playing the part of your mother or father the Creole comes out. (Interview with Cinous)

He elaborates on this, saying all three producer/presenters learn from their listeners too:

\begin{abstract}
Instead of just using a phrase or two [in Creole], sometimes the word itself will change... At first I think it was on purpose, but now it's a bit subconscious. Sometimes we don't realize. The fact that they [our listeners] can learn from us, and the back and forth makes it so much easier for them, not only to tune in, but also to learn.

The cool thing about being interactive with our listeners is that they'll call in and define a word, and I'll be like, I've heard this phrase my whole life... so believe it or not we're teaching Creole at the same time. They're teaching us too. (Interview with Cinous)
\end{abstract}

In The Morning Drive, voice, accent and language have particular complex functions, creating and sustaining connections between community identity (also characterized here by the duality produced through migration and movement) and community histories and articulating this web of experiences through a richly combined flow of Creole segueing into English and back again into Creole, oat times within a single sentence. In a radio text, voice narrates and narrativizes, providing both structure and topic, and establishes a point of view and of identification for the listener. In talk radio, given sufficient time on air, voice can be deployed in process by a given speaker in the form of an individual narrative (Couldry 2010) which serves as a situated "account, implicitly or explicitly, of the world within which they act” in Nick Couldry's formulation. (Couldry 2010: 7) Couldry argues for the importance for everyone to have access to means to enable them to give such an "account of oneself" as a way of articulating individual identity.

Building on my use and explanation of the concept of accented radio at the start of this chapter, I suggest the above programs function as examples accented radio, facilitating articulations of specific cultural, ethnic and linguistic subjectivities simultaneously shaped by the communication structures of the hosting locality. (Moylan 2013) In the current context of what Barnor Hesse identifies as a post-racial horizon, characterized by a "socially recurrent blindness to racism," (2011: 155) marginalized and minority communities of brown and black people remain under-represented or depicted via harmful representative forms. Community radio facilitates self-expression of marginalized and minority communities in accented modes of articulation particular to the given community, broadcasting on radio shows produced by and for communities to speak from and to their particular experiences. 


\section{REFERENCES}

Barnard, Stephen (2000): Studying Radio, New York: Hodder Arnold.

Couldry, Nick (2010): Why Voice Matters: Culture and Politics after Neoliberalism, London: Sage.

Gordon, Janey (ed.) (2009): Notions of Community: A Collection of Community Media Debates and Dilemmas, Oxford: Peter Lang.

Hartley, John (2000): “Radiocracy: Sound and Citizenship”, In: International Journal of Cultural Studies, 3/2, pp. 153-159.

Hendy, David (2000): Radio in the Global Age, Cambridge: Polity Press.

Hesse, Barnor (2011) "Self-Fulfilling Prophecy: The Postracial Horizon." In: The South Atlantic Quarterly, Winter 2011, pp.155-178.

Langer, John (2005): "Multicultural Radio in the Global Era: The Canadian Broadcaster Perspective.” In: Australasian Canadian Studies, 23/2, pp. 113-140

Lewis, Peter M. (2008) Promoting Social Cohesion: The Role of Community Media, Strasbourg: Council of Europe.

Lewis, Peter/Booth, Jerry (1989): The Invisible Medium: Public, Commercial and Community Radio, London: Macmillan.

Moylan, Katie (2013): Broadcasting Diversity: Migrant Representation in Irish Radio, Bristol: Intellect.

Naficy, Hamid (2001): An Accented Cinema: Exilic and Diasporic Filmmaking, Princeton and Oxford: Princeton University Press.

Scifo, Salvatore (2008): “Editorial” In: Westminster Papers in Communication and Culture, 5/1, pp. 1-4.

Vertovec, S. (2008): “An Accented Radio: Fostering Cosmopolitanism Through Media in Berlin.” In: Rovisco, Magdalena/Nowicka, Maria. (eds.) Cosmopolitanism in Practice, London: Routledge, pp. 184-204. 